This item was submitted to Loughborough's Research Repository by the author.

Items in Figshare are protected by copyright, with all rights reserved, unless otherwise indicated.

\title{
Client-centred design evolution via functional prototyping
}

PLEASE CITE THE PUBLISHED VERSION

http://dx.doi.org/10.1504/IJPD.2009.023747

PUBLISHER

() Inderscience

VERSION

AM (Accepted Manuscript)

LICENCE

CC BY-NC-ND 4.0

REPOSITORY RECORD

de Beer, D.J., R.I. Campbell, M. Truscott, L. Barnard, and G.J. Booysen. 2019. "Client-centred Design Evolution via Functional Prototyping". figshare. https://hdl.handle.net/2134/10891. 
This item was submitted to Loughborough's Institutional Repository (https://dspace.lboro.ac.uk/) by the author and is made available under the following Creative Commons Licence conditions.

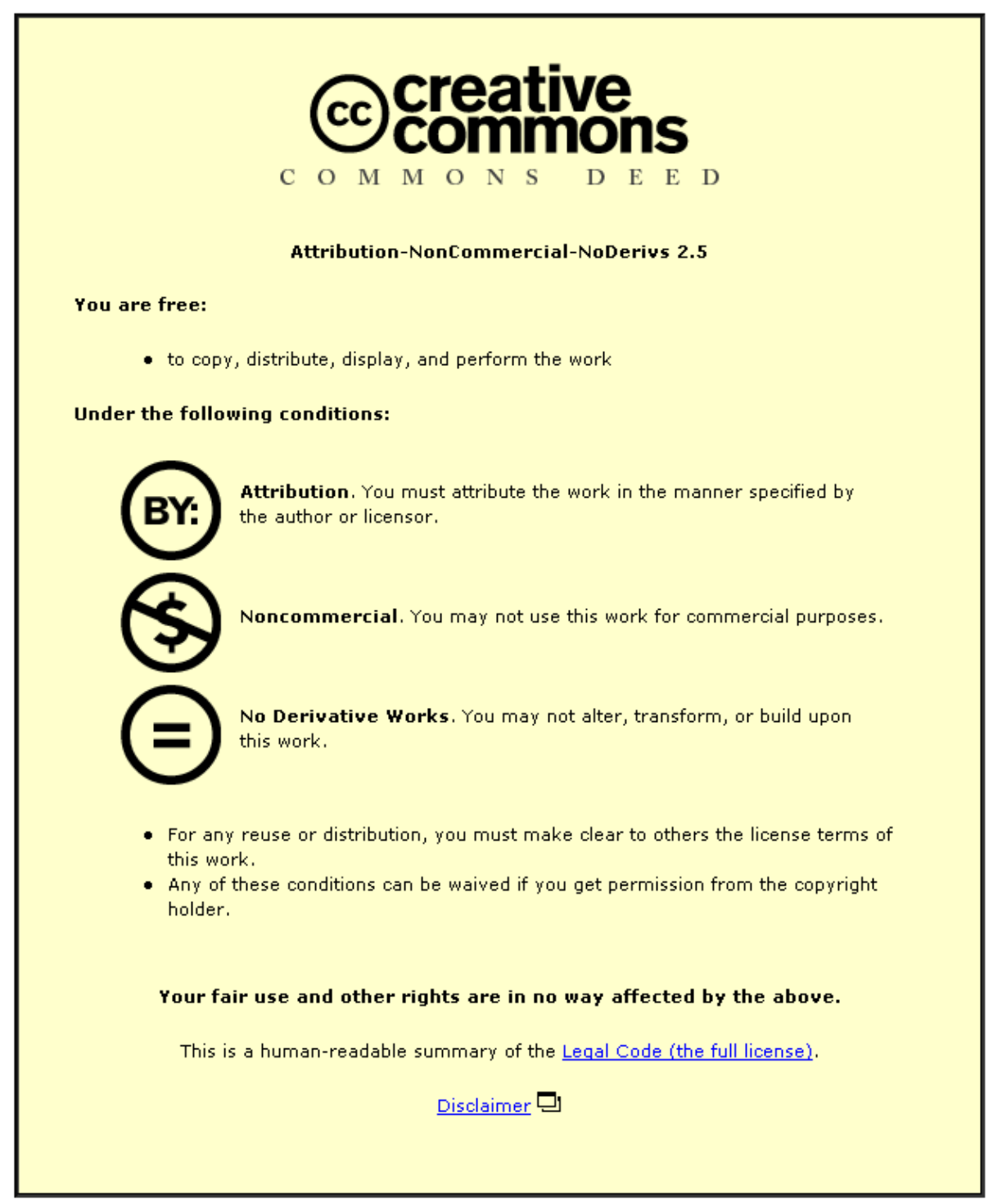

For the full text of this licence, please go to: http://creativecommons.org/licenses/by-nc-nd/2.5/ 


\title{
Client-centred Design Evolution via Functional Prototyping
}

\author{
Authors: DJ de Beer*, RI Campbell**, M Truscott*, LJ Barnard*, GJ Booysen*
}

\section{* - Based at the Central University of Technology, Free State \\ **- Visiting Scientist at the Central University of Technology, Free State}

\begin{abstract}
Product design is often still a procedure that involves a sequential approach, with various groups or individuals involved at different times in the process. Successful product design thus becomes, amongst other things, a function of good communication. Various authors have referred to a lack of communication as the "over the wall" phenomena, and have described how participants in the product design process undertake their own tasks and then pass the product on to the next player in the (sequential) process. The increasing popularity of concurrent product development techniques has helped to reduce the sequential nature of design but poor communication can still be a problem. Concurrent product development and data management processes help design team members to communicate but the customer often is still outside the process. The use of Rapid Prototyping to generate functional prototyping models is emerging as a new type of communication system. As well as facilitating communication within the design team, it can also keep the client involved in every step of the product evolution process. This paper introduces research work undertaken at the Central University of Technology, Free State to show how having customer input through their use of physical prototypes throughout the design process, can change the traditional product design paradigm. This is conducive to accelerated product development, but still sensitive to the client's needs. Furthermore, replacing the digital data or virtual model with a real product model (one which can be touched, experienced, tested, etc), brings a new dimension of "natural" communication into the concurrent product development approach.
\end{abstract}

Keywords: product design, communication, prototypes, customer involvement

\section{Introduction}

Product design is often the determination of a perceived solution for an assumed need, based on another assumption that the need has been recognised or understood by the designer. The design process should therefore involve two-way communication between the designer and the client, i.e. communication of the need to the designer and communication of potential design solutions to the client. Traditionally, industrial designers have used 2D sketches together with hand-made models to communicate form and aesthetics to their clients. However, the sketches are not always easy for a layperson to evaluate aesthetically as they may exhibit some degree of "stylisation" rather than a straightforward representation of the design intent (see figure 1). Also, the models have the limitation that they cannot be functionally evaluated. This is because the combination of aesthetic and functional characteristics in a single model has often been difficult or impossible (Evans, PhD, 2002). More recently, designers have begun to recognise that rapid prototypes can be used for this purpose. Rapid prototyping (RP) is the collective name for a set of technologies and processes used to manufacture models directly from three-dimensional (3D) CAD data by building them as a series of layers. Commonly used RP processes include Stereolithography 
(SL), Laser Sintering (LS), Fused Deposition Modeling (FDM) and 3-Dimensional Printing (3DP). RP technologies have gained diversity, complexity, sophistication and popularity since their introduction in the late 1980's. It is not the aim of this paper to describe the various RP processes, as they are well documented elsewhere (Wohlers, 2005). However, it is important to recognise that the use of RP to develop combined aesthetic/functional models is emerging as a powerful designer's communication tool to keep the client closely involved in the early stages of the product development process (Evans and Campbell, 2003).

\section{Take in Figure 1}

Engineering teams also use a range of physical models during the detail design of a product, e.g. breadboards and standard enclosures to package their functional devices, mock-ups for assembly evaluation and prototypes for performance evaluation. Often, these models are not faithful to the original design concept inherited from the industrial designer since they may have been simplified or standardised to ease their manufacture. This is a recipe for misrepresentation of the client's needs and can lead to unwarranted detours in the development phase, resulting in costly iterations, redesign and ultimately, late market entry. Therefore, engineers have started to rely more heavily upon prototypes that are created directly from the original design data, either via RP or through the use of virtual prototypes. However, these prototypes (especially if virtual in nature) are rarely used for further verification of customer requirements until very late in the product development process, e.g. "beta-testing" of the product. This is because virtual prototypes are often inaccessible to the layperson and RP models have been seen as "too precious" to allow them to be potentially roughly handled (Cain, 2005).

The paper introduces research work undertaken at the Central University of Technology, Free State to show how customer input derived from evaluation of physical prototypes can be used throughout the entire design process. This challenges the traditional mechanical design paradigm which only involves the customer at the start and finish of the design process. Instead, a client-centred design evolution process is proposed, still conducive to accelerated product development, but also highly sensitive to the client's needs.

\section{Problem Definition - The Traditional (Mechanical) Design Paradigm}

Design is sometimes seen from a very conservative "mechanical” viewpoint. It is typically understood to be an iterative procedure, as described by Shigley and Mitchell (Shigley and Mitchell, 1998), consisting of a number of phases, such as recognition of need; definition of the problem; synthesis; analysis and optimisation; evaluation and finally, presentation. (see figure 2). In keeping with this viewpoint, the first step arises from a specific need, or an identified problem (bearing in mind that this may be only perceived rather than proven, as stated in the Introduction). Defining the problem is a more specific (categorical almost) description of the problem and the boundaries in which the designer / design team should operate. It can also forecast the expected or required outcomes. Boundaries set out in the definition phase should clearly indicate the constraints and criteria to be met by the design or development, and should ultimately be applicable during evaluation of the product. These constraints and criteria are often captured in the form of a product Design Specification (PDS). Whilst constraints would normally specify the maximum or minimum target values applicable to the design, criteria should also define its quality, i.e. its "fitness for purpose". This step should set out the parameters to be used to evaluate not only one design, but also to 
compare different design alternatives with each other. Typically, the "best" design will be the one which has the optimum combination of criteria values. The careful selection of these criteria forms an integral part of the definition of the problem, and provides a wellrecognised opportunity for capturing the customer's inputs or requirements.

\section{Take in Figure 2}

Following the definition of the problem, synthesis, analysis and optimisation together form constituent parts of an iterative process. A design is created with the aim of meeting all the constraints (synthesised) and then analysed to determine whether the set of criteria has been satisfied. If the analysis indicates that the criteria have not been satisfied, or that some criteria could be improved upon, it should lead to modification of the design, and hence, further analysis. If any major shortcomings are observed in this phase, the design must return to the synthesis phase to identify alternative solutions. Obviously, these iterations could be performed a number of times, before an ideal, or at least suitable, design is found. Final evaluation and presentation of the finished design to the manufacturing operation can then proceed.

When following the steps outlined above, design optimisation often remains a serial process, with a series of analyses performed step by step using different virtual and physical prototypes. Depending on the nature of the product, the development environment or even the final method of manufacturing, such analyses could include determination of aesthetic impact, usability conformance, mechanical stress levels, thermal performance, manufacturability, etc. This may involve the use of finite element analysis, mathematical process modelling, physical testing and appearance prototyping. If done in series, this could be a very time-consuming process, as tasks will be performed sequentially. More critically, a part may pass a stress analysis, only to fail a manufacturing requirement. Subsequent manufacturability modifications may be detrimental to the stress results and this could easily cause an oscillation between two or more constraints, leading to a protracted optimisation exercises (see figure 3).

\section{Take in Figure 3}

The benefit of using a physical prototype to do all of the form, fit and functional analysis, during the analysis of the design, should be clear. Such a physical prototype would enable testing and comparison against all the constraints for feasibility. Also, it allows measurement of the criteria variables. It can be readily understood and used by designers, engineers and customers, alike. However, synthesising the information through a physical prototype is still not common practice (Cain et al, 2003). The authors suggest that there is a two-fold problem with the traditional mechanical design paradigm. Firstly, it is difficult to ensure a simultaneous match to all the design constraints and secondly, the customer is largely excluded after their initial input into the definition of the design problem.

\section{A Partial Solution - Concurrent Product Development}

A partial solution to this problem is the Parallel, Simultaneous or Concurrent Engineering or Product Development philosophy. Concurrent Product Development (CPD) refers to an approach to product design whereby companies attempt to reduce the lapsed time required to bring a new product to the market through the integration of design, engineering, 
manufacturing, and other functions within the organisation. During early development, following a procedure of continual review of the evolving design and suggesting changes, the total product development cycle may typically be reduced by $30 \%$ to $70 \%$ (Charney, 1991). This approach opens up the opportunity for all analyses to be done simultaneously, with improved communication within the (multidisciplinary) development team (de Beer, 2003). Basing the new design not only on the result of one analysis, but on the results of the total analysis package, may reduce the oscillation effect between different parameters. A CPD design concept must not satisfy only strength and manufacturability for example, but address all pertinent criteria, and this should be done simultaneously during each design iteration. However, for the analyses to be truly simultaneous, a single prototype that can be easily modified between each iteration is required.

Product quality is very often a function of design, rather than a function of manufacturing (i.e. through inspection and measurement). From this viewpoint, a successful product will be one that satisfyies customer needs, whilst providing superior value (Kotler and Armstrong, 1999). To create such a product (of superior value), customers' needs have to be fully understood, which emphasises the need to focus on some form of Quality Function Deployment (QFD). QFD, when performed with full understanding of the process and with adequate effort to collect and analyse the required data, is a powerful tool that addresses the shortcomings that are common in product development. It enables the "voice of the customer" to be cascaded throughout the product development process. However, the desire to avoid "over the wall design" (Groover, 1996) within CPD has also led to the increased use of a range of techniques such as Design for Manufacturing, Assembly and Disassembly, Design for Quality, Design for Life Cycle, Design for Cost, etc. Attending to all of these detailed and rigorous methods may lead to designers ignoring rather than involving the customer, thus defying the whole objective of QFD. Enabling the customer to be more easily integrated into the design process would help to overcome this. In response to this need, it is proposed that the utilisation of digital technologies (such as RP) to assist design analysis can also open up new communication channels to facilitate increased client involvement within a Concurrent Product Development approach.

\section{Using Functional Prototypes and Customer Input to Drive the Design Process}

The case study presented in the remainder of this paper is a prime example of how functional models created using RP can be used to change the whole design chain, by bringing client inputs into all the phases of the design process in support of concurrent product development. It demonstrates how the two remaining CPD requirements, i.e. truly simultaneous design analyses and continual customer involvement, can be met via one method, customer interaction with physical models.

\subsection{Recognition of Need, Definition of Problem, Initial Synthesis and Analysis}

Many products exist for use within the advertising/display market. However, Technimark (a Cape Town-based product development company), through involvement with a portable system that could display banners in a bowed form, self-tensioned via the system's structure, identified the need for an improved self-tensioning display-system. A number of concepts were generated that potentially satisfied the design problem and a preferred solution that used standard gas struts as the vertical tensioning mechanism for the banners was taken forward to a more detailed level of design. Attaching the banners to composite rods that 
create a natural bow once constrained at both ends would form the bowed shape. Various versions of this concept were tested and physical prototypes were manufactured using laser cutting, CNC punching and bending and manual assembly (see figure 4). However, when the client tested the prototypes, they did not function to expectations.

Take in Figure 4

\subsection{Re-Definition of Problem}

The design problem was reconsidered keeping the original objective to tension a banner in mind. The outcome, obtained with the client's input, was to design a custom-manufactured device that would, upon application, apply tension to the banner. Having identified the device as the crucial part of the overall banner tensioning need, the next agreement between the designers and the client was that this would be a separate self-tensioning unit (and not a complete system), which opened up endless deployment possibilities. The design problem was therefore re-defined with the following constraints:

- The device would be a free-standing unit

- It should be mountable on walls, frames and other structures

- It should be able to hold banners of up to six meters in length

- The units would be deployed in sets of six or more to tension and display each banner.

- The tensioning distance should be up to approximately $80 \mathrm{~mm}$ linear travel

- The tensioning force at this distance should be approximately $10 \mathrm{~kg}$

Having re-defined the problem, a second attempt at synthesis was made and the iterative process of analysis and optimisation began.

\subsection{Iterative Design Evolution of the Self-Tensioning Unit}

Tensioning was achieved in concept MK1 through a spring-loader that moved vertically in the main body of the unit (see figure 5a), with variable mounting-angles made possible by using a cylindrical hinged pin, located in a slider (see figure $5 \mathrm{~b}$ ). The base and cover were assembled using screw-fixing (see figure 5c). Design curves and lines were defined and experimented with to achieve an acceptable level of aesthetics. Prototypes were produced using laser sintering (LS) and tested by means of putting up a $1 \mathrm{~m} \times 2 \mathrm{~m}$ banner on a simple structure. Testing the prototyped units showed that the curvature of the flexible carbon fibre batten (visible in figure 5b) used between two units caused the hinge pin to be dislodged out of the slider.

\section{Take in Figure 5}

Through assessment which involved the client, a number of possible design improvements were identified, such as to get rid of screw-holes by using snap-fittings and replacing the round-hinged pin with a T-Profile mount-block at a fixed angle (see figure 6a). Angle variation could be achieved with dedicated parts designed for required / preset angles (see figure $6 \mathrm{~b}$ ). The square button seen above the mount-blocks was for locking them in position. Once more, LS prototypes were produced and tested with physical load, as a functional evaluation of the design. The twist force transferred by the flexible carbon fibre batten caused the slider to jam. Springs with a different stiffness value were used, but without any real improvement of the situation. Again, the tests were only made possible through having physical prototypes available. 
Using customer inputs together with the design team's opinions, the locking button was omitted, resulting in a shorter unit. The locking button was judged unnecessary based on the evaluation of the physical prototype. An off-the-shelf aluminium extrusion, bent to achieve the desire bow profile, omitted any twist-force being exerted on the units (see figure 7a). The T-profile mount-block part was replaced by two functional parts located in the unit's T-slot and connected to the second part via a hinge pin (see figure $7 \mathrm{~b}$ ). The second part was screwfixed to the aluminium extrusion - accommodating any angle, due to the swivel action (see figure $7 c)$.

\section{Take in Figure 7}

Through physical testing and evaluation with the client, the following shortcomings were identified:

- Mounting of the four units on a wall proved to be very difficult - especially achieving horizontal and vertical alignment;

- The rail mount-block was bulky, which required that the sock of the banner be large enough to feed the Aluminium rail through it, with the mount-block already attached;

- The pockets of the banner-sock needed to have holes cut in them in order for the rail mount-block's swivel end to have access to the slider on the Self-Tensioning Unit;

- With the rail mount-block fixed to the Aluminium rails, it cannot be guaranteed that if the prints need to be changed within the store, the same rail will end up at the same set of mounted self-tensioning units. Inter-operability cannot therefore be guaranteed;

- The entire installation, assembly of the print and changing it were major concerns identified, and alternative solutions had to be found.

These prototypes were also taken to the client in the UK for demonstration purposes and to get possible commitments for orders. Positive feedback was received from all of the client's team-members, but identified the following further needs:

- It would be beneficial not to have to drill any holes in order to install a unit. If standard shelving rails could be utilised, this would be of great practical benefit. (The same standard is used throughout the specific chain of stores targeted).

- The unit must not be visible to customers, only the print on the wall must be seen. The unit must be hidden behind the print at all times.

Taking all of the client's needs and opinions into account, the slider was adjusted to extend beyond the unit to ensure that the unit will be covered by the banner at all times - even in its lowest position (see figure 8a). A push-button mechanism was incorporated to lock the slider in either the top or bottom position and only needs to be pressed to move the slider. When pressing the button, the spring will shoot the slider to the top position (see figure 8b) where it will again lock in place. This feature addressed the issue of simplifying the banner display process tremendously.

\section{Take in Figure 8}

Allowance was made for a slide-in mounting bracket in the base part of the Self-Tensioning unit (see figure 9a). This feature helped to address the design requirement that the fixing of 
the unit must be able to utilise the existing standard structures. A mounting adaptor plate (see figure 9b) could now be developed for each specific client requirements, since it can be implemented into the standard system of such a client.

\section{Take in Figure 9}

Fittings and brackets were designed to attach the unit to the client's internal mount rail, as in all their stores (see figure 10a), together with a special designed extrusion (see figure 10b). Using a slide and guide method for the rail mount-block implied no need for screw-fixing and also placed less importance on pitch-spacing. The changes also resulted into a much simpler way to fix the banner to the rail (see figure 10c). It furthermore contributed to easing the assembly and putting up of the unit. The method used to secure the print is readily available commercial system, resulting in a much smaller banner sock to accommodate the plastic extrusion; easier feeding through the sock and allows fast and easy changing of banners. The design was now judged to have met all necessary constraints and criteria.

Take in Figure 10

\subsection{Evaluation of the Final Design}

Prototypes were produced from the final design iteration were tested by the design team and evaluated by the client. The performance results and feedback obtained from the entire team (including the customer) generated enough confidence to rapid manufacture a full set of ten Self-Tensioning Units, using LS. The units were finished-off and sprayed in the specific colour required by the client (similar to the standard colour of their rails and shelving systems). The units were couriered to the UK and installed in the client's marketing store for all the various other departments to evaluate the system. Once again, the results obtained were positive.

\subsection{Presentation to Manufacturing Operation}

Due to the design solution being tailored around the client's specific requirements and the fact that the design solution could be tested and evaluated upfront, the clients considered themselves to be an integrated part of the development process and also felt confident that their specific requirements had been met. Based on these factors, a provisional order of 45 000 Self Tensioning Units were placed subsequent to the approval of the final injectionmoulded components and units. Moulds have been completed and the off-tool samples evaluated by the client.

\section{Discussion}

This case study demonstrates the utilisation of functional prototypes that enable complete design iterations (involving analysis of all design criteria) to be repeatedly undertaken until an optimised design is reached. This was possible because the RP/RM prototypes were sufficiently similar to the final product for all functional testing and client evaluation to be completed with a high degree of confidence. In addition, the provision of fully functional prototypes also acted as the catalyst for stimulation of further ideas and development during the product evolution. A particular benefit of RP/RM prototypes was that they were readily understood by everyone involved and facilitated communication between the industrial 
designers, engineering designers, manufacturing engineers and even the target client. They performed an analogous role to virtual prototypes within the domain of PDM (product data management). In PDM, members of the product development team have remote access to the virtual prototype as shown in figure 11a and can perform their own specific analysis upon it. The PDM network can also act as a medium for communication between team members. As such, PDM/virtual prototyping is advanced as a means of breaking down the barrier between engineering design and manufacturing.

\section{Take in Figure 11}

A functional RP/RM prototype can act in a similar way (figure 11b) but has the added advantages of being portable, more widely understood and accessible to several people at the same time and place (rarely the case with virtual prototypes). This is indicated by the "cluster" members in figure 11b being shown as more numerous, and in actual contact with the prototype and with one another. Network members $M$ and $S$ in figure 11a represent the Marketing and Sales departments/functions respectively and it could be assumed that in the past these would have been the only two interfaces between the client and the product development team. $M$ would have been an input from the customer, whilst $S$ would be considered as an output to the customer or at most, a final evaluation, with little or no opportunity to feed this back into the design loop. Analysis of the results achieved through having the client involved in the complete design evolution indicates that the client actually became part of the iterative loop. Therefore, the client can be considered to interact with the whole of the functional prototype cluster, as indicated by the dashed line in figure 11b. Indeed, it could be argued that the customer effectively operated as an integral part of the physical prototype.

Customer inputs for new product development, too often stop with a user requirement statement. With a traditional sequential approach, iterative loops involving customers are costly exercises, as they normally have to wait until the detail design prototype is available and therefore introduce a substantial time delay into the design process if major changes are required. Figure 12 illustrates a design philosophy were functional prototypes are produced early and often as a central part of a highly iterative process. This creates the opportunity to receive customer inputs beyond the initial idea, since giving them the opportunity to experiment with certain parts or levels of a developed product, may stimulate creativity and innovation. It can even lead to a re-definition of the design problem at any time (as shown by the cyclic arrows in figure 12). This method has been termed Customer Interaction with Functional Prototypes (CIFP) and has proved itself to be invaluable in several product design projects (de Beer and Campbell, 2005).

Take in Figure 12

\section{Conclusions}

The positive results lead the authors to conclude that through customer involvement, the traditional design process can be changed from a design-team-only approach, to one where iterations driven by customer involvement and communicated through physical prototypes are both facilitated and welcomed. However, with customer input taking place throughout the process, the traditional sequential process must now become a fully parallel, iterative process that is highly sensitive to customer needs. Designers too must change. They must 
learn how to communicate with ordinary customers, especially in terms of listening, and they must be persuaded of the benefits that this extra effort will yield.

The role of the RP/RM prototypes was seen to be similar to that of sketches and mock-up models (sometimes called 3D sketches) within industrial design, i.e. for rapid and copious design iterations and as a communication medium amongst designers and between the design team and the client. However, sketches can only be used to evaluate aesthetics whereas functional models can be used to evaluate aesthetics, ergonomics, performance, manufacturability, etc. Therefore, it is possible that the use of functional prototypes could help to remove the barrier between industrial and engineering design since both can now employ the same communication medium.

Furthermore, Campbell et al (2003) discuss the potential of bespoke industrial design and manufacture, emphasising the potential for designing and manufacturing customised products according to individual customer needs. This will only be viable if customers can become an integral part of the design team. Therefore, it is postulated that the CIFP approach may also facilitate the evolution of high-value-added bespoke products, which are tailored precisely to customer's needs.

Finally, this would all seem to imply that the usage of physical prototypes is to preferred over virtual prototypes. However, a very important caveat that must be stated is that the use of functional RP/RM prototypes in this way is not suited to all types of products. Where product complexity is high and where repeated numerical modelling and analysis is required (e.g. in automotive vehicle design), virtual prototypes offer extensive benefits. However, even in these cases, it is expected that some product sub-systems will benefit from the CIFP approach.

\section{Acknowledgements}

The authors would like to acknowledge the inputs of the Technimark design team (Mr Alphons du Toit, Mr Dietmar Renner and Mr Hanno van Riet), as the Industrial partner to the Integrated Product Development Research Niche Area of the Central University of Technology (CUT). All designs have been made by Technimark.

Acknowledgement for financial support goes to the National Research Foundation (NRF), the Department of Trade and Industry (DTI) and the programme for Technology and Human Resources for Industry (THRIP).

We would further like to acknowledge inputs of the management, staff and students from the CUT's Centre for Rapid Prototyping and Manufacturing (CRPM) and the students who were involved

\section{References}

Cain, R., Campbell, R.I., Gyi, D., (2003), Managing Collaboration Between Designers and Users in the PD Process, Proceedings of the 2003 PDMA Research Forum , Barczak, G. (ed), Product Development and Management Association, Massachusetts, pp 35-54. 
Cain, R., (2005), Involving Users in the Design Process: The Role of Product Representations in Co-Designing, PhD Thesis, Department of Design and Technology, Loughborough University.

Campbell, R.I., Hague, R.J., Sener, B., Zhen, S. and Wormald, P.W., (2003) Re-inventing the wheelwright: The emergence of the digital artisan, Proceedings of 4th Annual RAPDASA Conference, DeBeer, D. (ed), Rapid Product Development Association of South Africa, Port Elizabeth, South Africa, 2003 , [CD-ROM].

Campbell, R.I., Hague, R.J., Sener, B. and Wormald, P.W., (2005), The Potential for the Bespoke Industrial Designer. The Design Journal, 6 (3), pp 24-34.

Cooper, K.G., (2001), Rapid Prototyping Technology-Selection and Application. New York: Marcel Dekker Inc.

de Beer, D.J., (2003), Rapid product Development - Technology or Process? Product Development management in a Concurrent Approach, Journal for New Generation Sciences, 1(1), pp 1-12.

de Beer, D.J. and Campbell, R.I. (2005), Concept Development through Functional Rapid Prototypes, Rapid Prototyping 11(4), Society of Manufacturing Engineers.

Groover, M.P., (1996), Fundamentals for modern manufacturing, materials, processes and systems, Prentice Hall International Editions.

Charney, C., (1991), Time to Market, Reducing Product Lead Time, Society of Manufacturing Engineers.

Evans, M.A., and Campbell, R.I., (2003), A comparative evaluation of design models produced using rapid prototyping and workshop-based fabrication techniques, Rapid Prototyping Journal, 9 (5), pp 344-351.

Kotler, P. and Armstrong, G., (1999), Principles of Marketing, Prentice Hall.

Shigley, J.E. and Mitchell, L.D., (1998), Mechanical Engineering Design, McGraw Hill.

Wohlers, T., (2005), Wohlers Report 2005. Rapid Prototyping, Tooling \& Manufacturing State of the Industry Annual Worldwide Progress Report. 


\section{Figures}

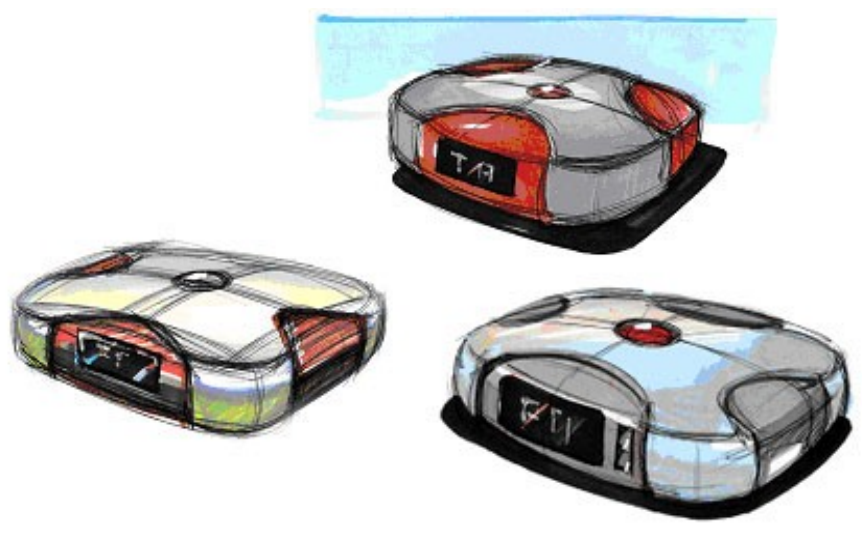

Figure 1: Typical stylised industrial designer’s sketch (Campbell et al, 2003). 


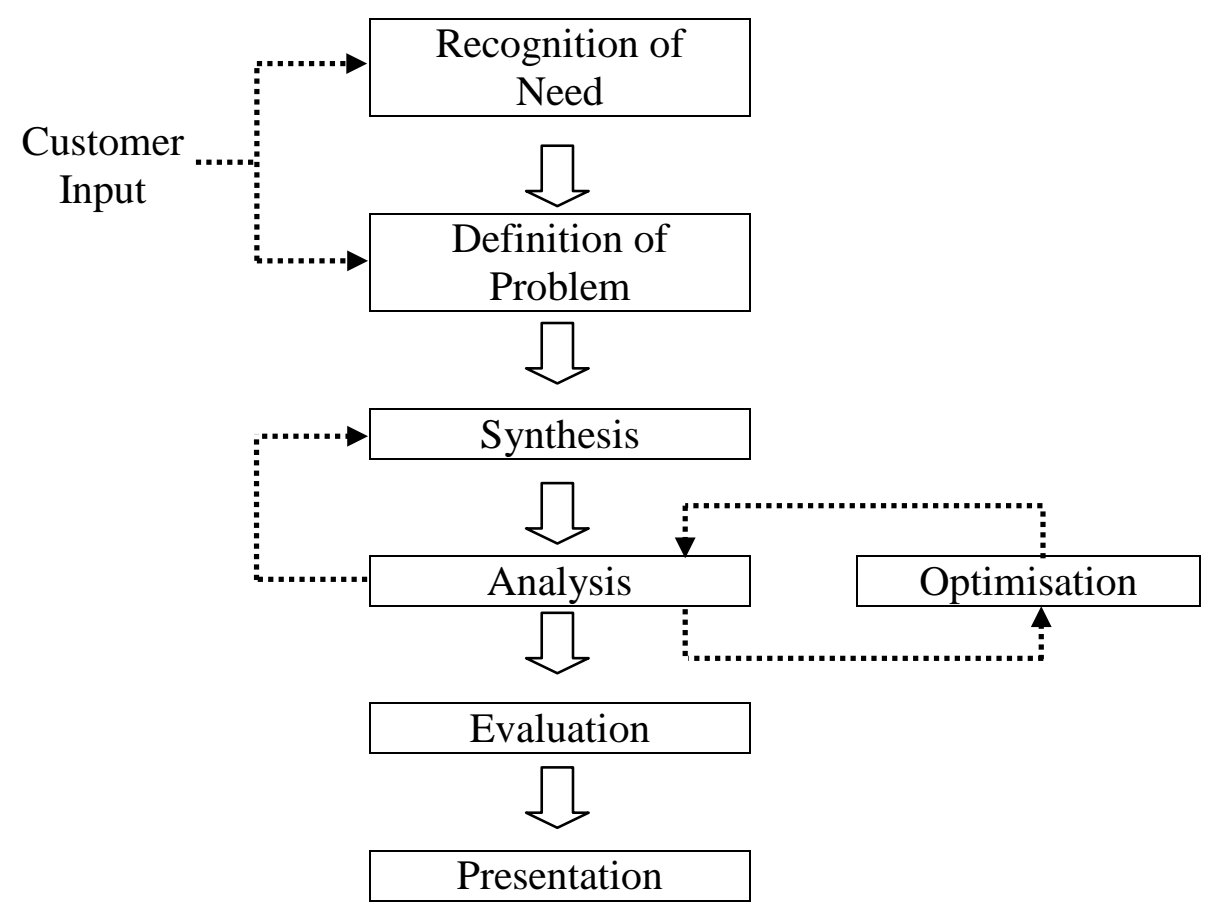

Figure 2: Typical representation of phases in the design process. 


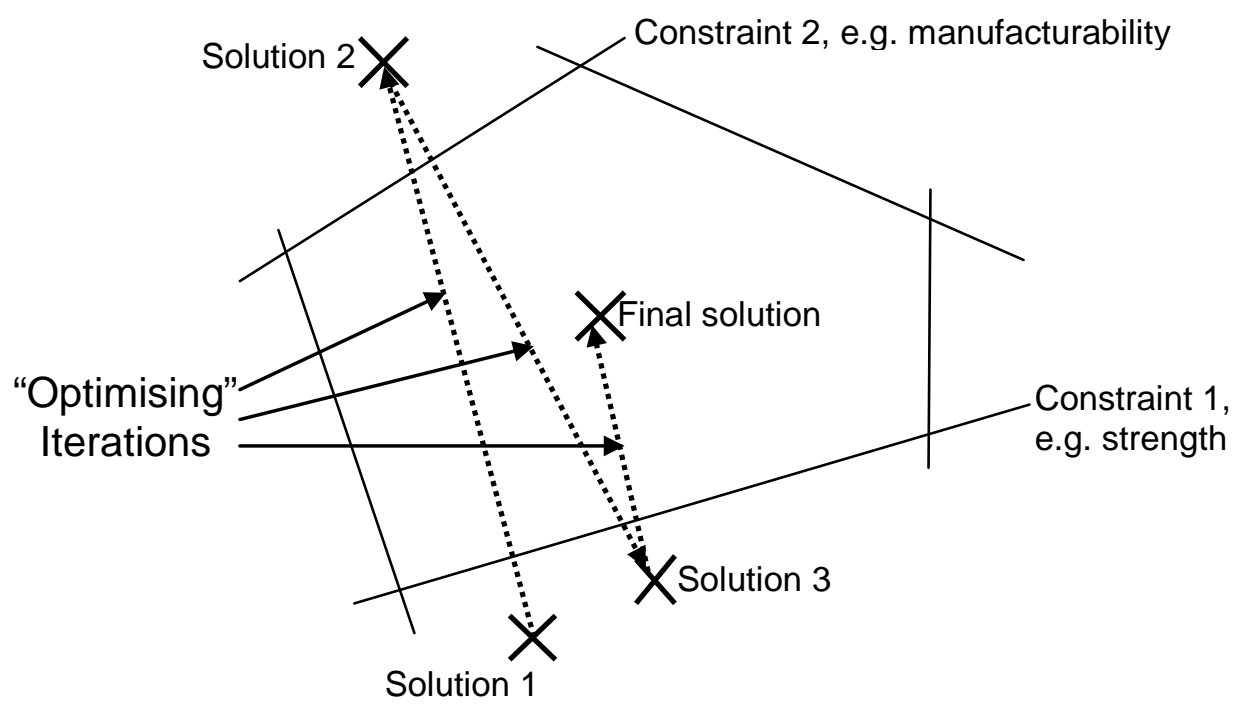

Figure 3: Problem of optimisation oscillation 


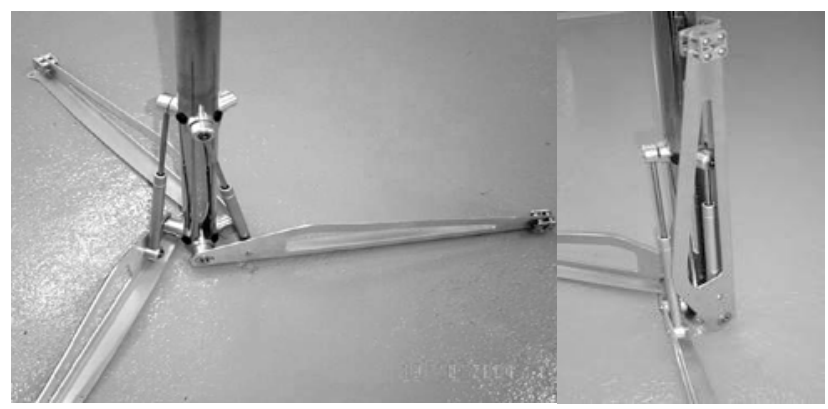

Figure 4: Manufactured version of original design. 


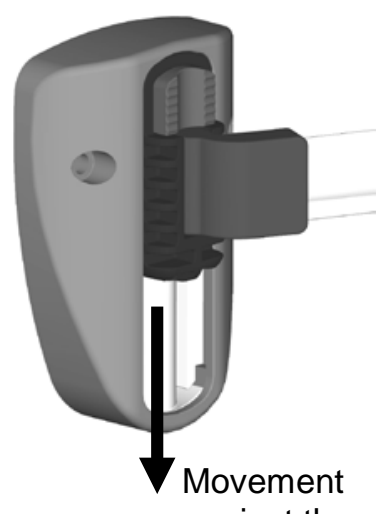

against the spring

(a)

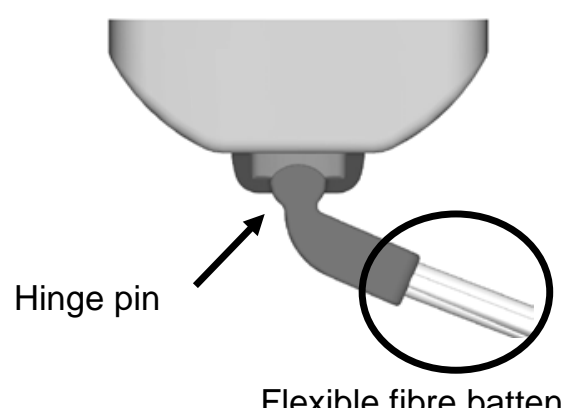

Flexible fibre batten

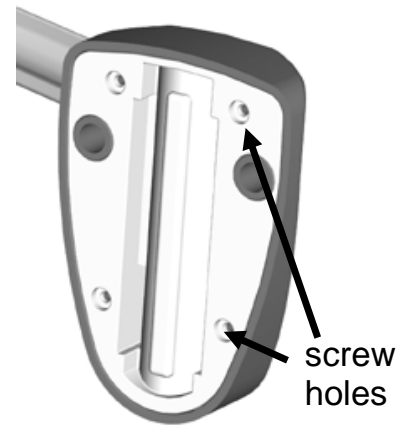

(c)

Figure 5: Design characteristics of the MK1 concept. 


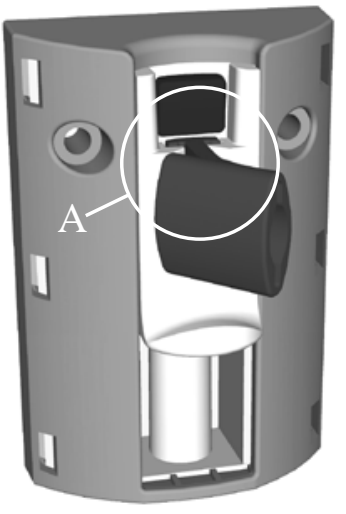

(a)

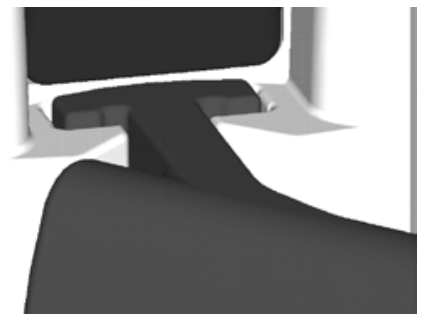

Enlargement of area inside circle A

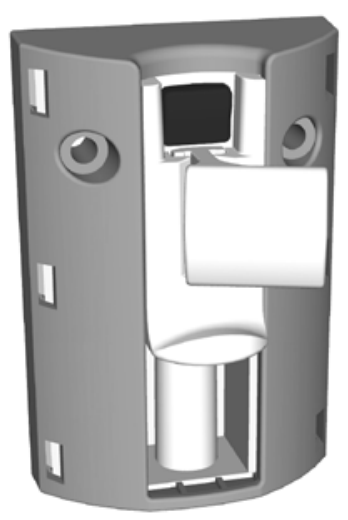

(b)

Figure 6: Design characteristics of the MK2 concept. 


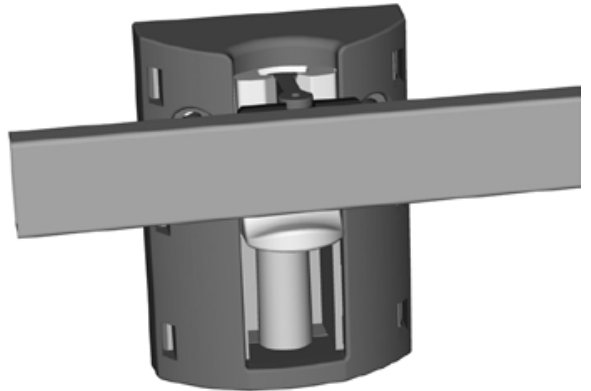

(a)

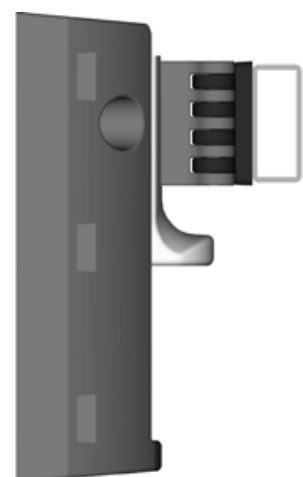

(b)

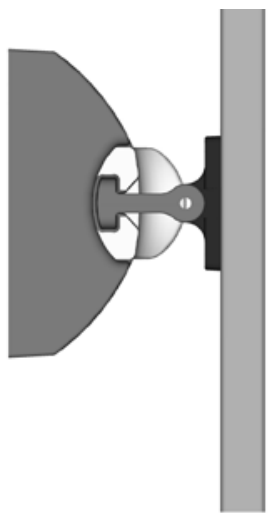

(C)

Figure 7: Design characteristics of the MK3 concept. 


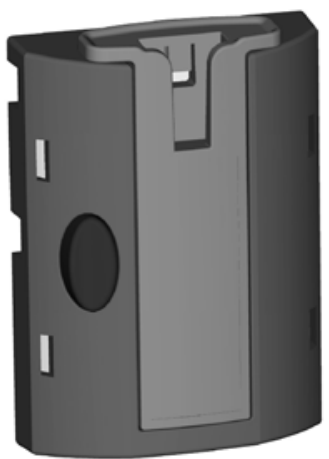

(a)

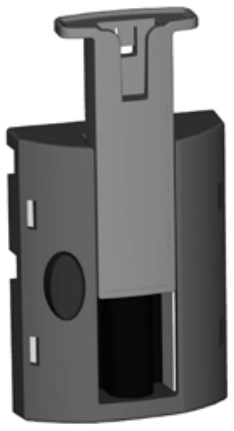

(b)

Figure 8: Bottom (a) and top position (b) of slider. 


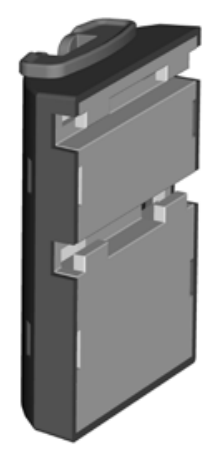

(a)

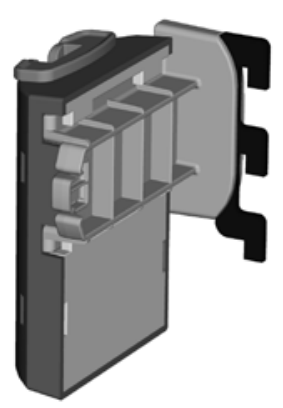

(b)

Figure 9: Slide-in mounting bracket an adaptor plate in the base part.

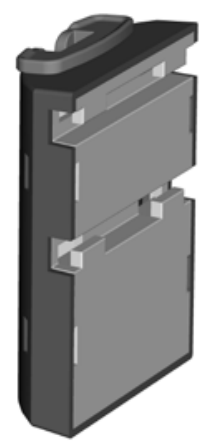

(a)

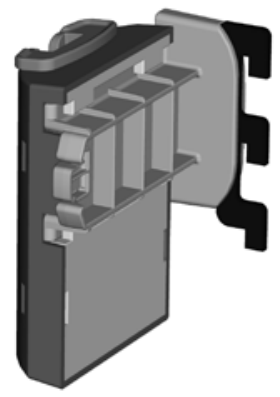

(b)

Figure 9: Slide-in mounting bracket an adaptor plate in the base part. 


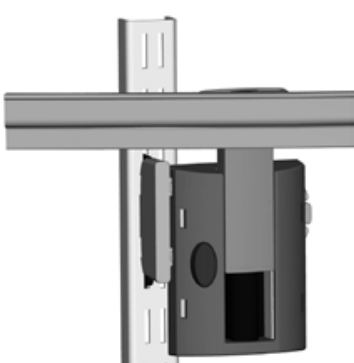

(a)

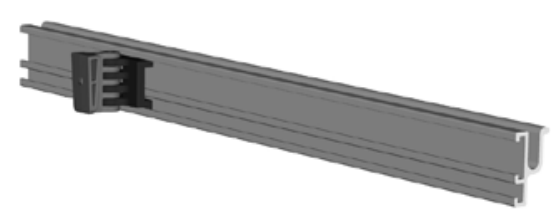

(b)

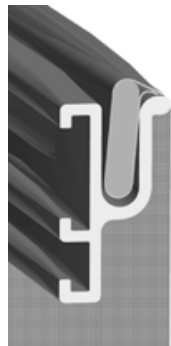

(c)

Figure 10: Attachment to client's rail. 


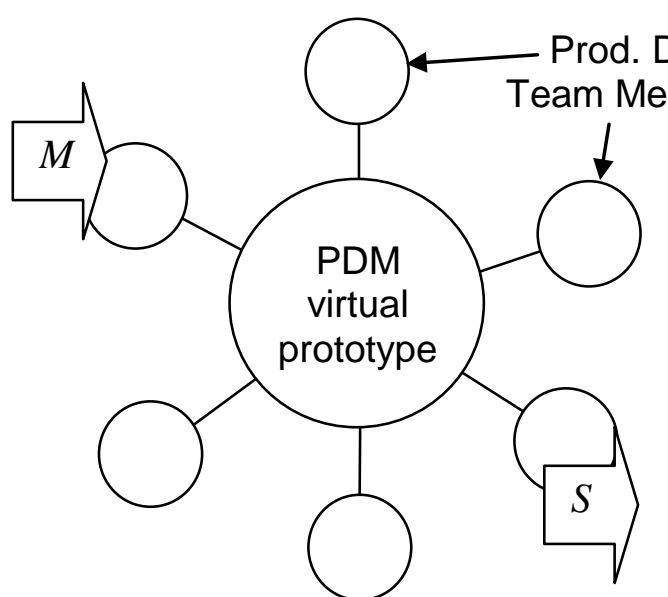

(a)

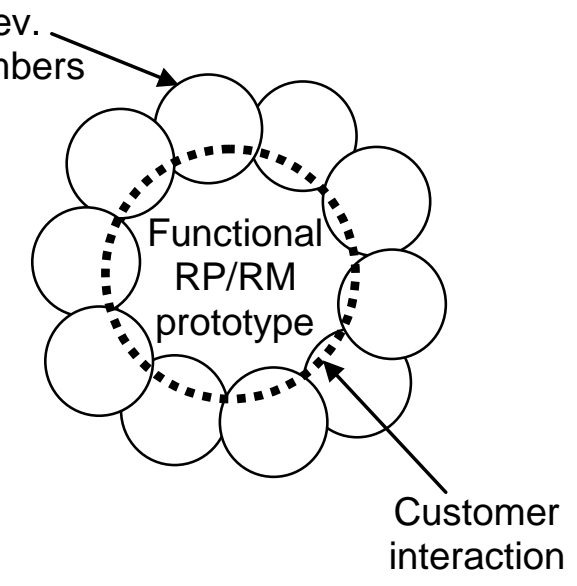

(b)

Figure 11: Analogy between PDM network and functional prototype cluster. 


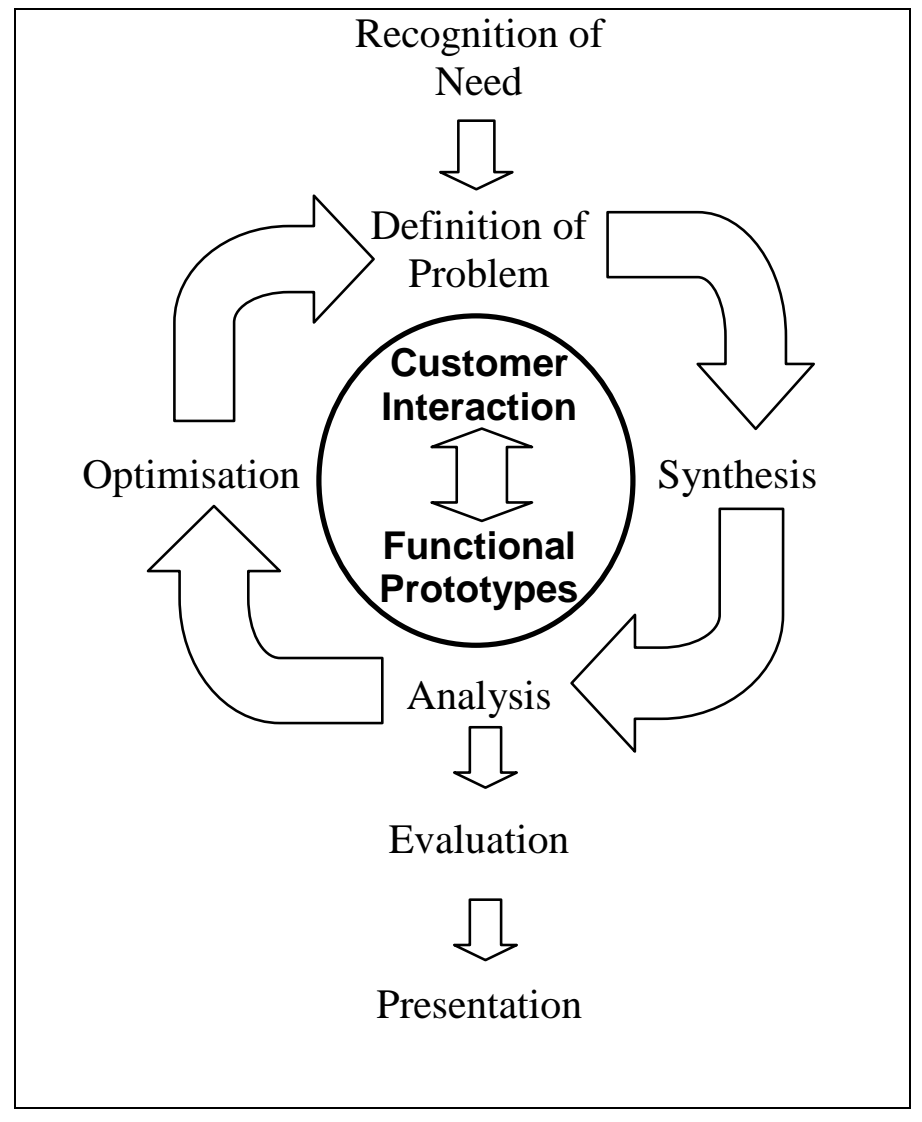

Figure 12: The central role of functional prototypes to generate customer interaction. 